\title{
Personalized Approach to Professional Development of "Helping" Professions Specialists
}

\author{
Natalya Ivanovna Nikitina ${ }^{1}$ \\ Tatyana Engersovna Galkina1 \\ Natalya losifovna Agronina1 \\ Svetlana Nikolaevna Tolstikova² \\ Veronica Mickhailovna Grebennikova ${ }^{3}$

\begin{abstract}
${ }^{1}$ Russian State Social University, Moscow, Russian Federation
${ }_{2}^{2}$ Moscow City Pedagogical University, Moscow, Russian Federation

${ }^{3}$ Kuban State University, Krasnodar, Russian Federation

Correspondence: Natalya Ivanovna Nikitina, Faculty of Social Work, Pedagogy and Uvenology
\end{abstract} \\ Russian State Social University, Moscow, 129226, Russian Federation. E-mail: nn0803@mail.ru
}

\section{Doi:10.5901/mjss.2015.v6n5s4p437}

\section{Abstract}

In modern Russia the problem of personalized approach in the system of refresher training of "helping" professions specialists (social workers, psychologists, and social pedagogues) is one of the urgent problems of professional education pedagogy. The article explains its authors ' position to the nature of personalized approach in the system of postgraduate education of social profile professionals, as well as the principles (temporality, potentiality, clusternode, positivity, predictability, socio-pedagogical support of an adult student individuality, etc.), conditions, substantial-technological basis for the implementation of this approach. The authors of the article in theory summarize the extensive empirical material, which was obtained by them as a result of their research work in the period from 2000 to 2015 at improvement of qualification and professional retraining courses for social workers, psychologists, social pedagogues, education managers in a number of Russian universities. The article considers features (diagnostic, predictive, reflective-compensatory, professionally responsible, constructive and transformative, adaptive-environmental, preventive, creative and developmental), stages (analytical and marketing, diagnostic and orientation, organizational, procedural, expert monitoring), performance criteria for the implementation of personalized approach in the system of additional professional education of social sphere specialists (subjective-personal, professional, objective, constructive and didactic criteria); the data on the value (positive dynamics) of satisfaction index of personalized approach implementation at their own courses, which refresher training faculties graduates in a number of Russian universities showed.

Keywords: personalized approach, social workers, advanced training, professional retraining, social pedagogues, and adult education

\section{Introduction}

In the last decade, the Russian system of postgraduate education of social sphere staff is developing in the economic context of market relations penetration in the sphere of vocational education services. This situation encourages agencies that implement improvement of professional skills programs, in a timely manner (quickly) respond to requests from representatives of professional associations and social and state order in terms of specialists retraining, and to observe educational services and labour markets, to implement staff-technology vocational training taking into account the individualization of cognitive, vocational and educational needs of students (practitioners).

In the modern world professional assistance to people in difficult life situations, can and should be a coordinated activity of a wide spectrum of humanities and social professions representatives (social workers, psychologists, teachers, professionals working with young people, health workers, lawyers, etc.). Proceeding from above stated, in this article the problem of postgraduate professional education of specialists of "helping" profile personification was studied in relation to trainees, members and administrative employees of institutions of population social protection, education, health.

According to the authors, personalized approach postulates understanding of a subject taught in the system of postgraduate professional education as a complex, multilevel, open, self-organized system that has an ability to keep 
itself in a state of dynamic equilibrium and to generate new forms of their life organization. This approach expresses the requirement to let adult students (students of the training) select options of educational routes, programs, educational services, training on individual educational trajectories in accordance with individual capabilities, changing cognitive needs, and career prospects. The implementation of this approach relies on the internal resources of an adult student personality, provides development and implementation of individual programs of professional and personal specialist's growth.

Science has accumulated a certain potential for theoretical-methodological and applied aspects development of social sphere specialists postgraduate education personification problem. Justification of continuing education phenomenology as a lifelong enrichment of resource potential of a specialist at personal, professional and social levels represented in a number of researchers the works (Arnold, 2003; Asmolov, Verbitsky, \& Gusairov, 1993; Brennan, 2001; Correa, 1973; Nikitin, 2003; Onushkin, 1989; Sumi, 2007; Wershlowski, 2002; Zmeev, 1999).

Many works describe informative, methodical and qualitative aspects of continuous professional training of social sphere specialists in system "college—university-postgraduate education (professional development and professional retraining)" (Angell, Heffernan, \& Megicks, 2008; Barsky, 2009; Bitusikova et al., 2010; Bocharova, 1999; Doel \& Shardlow, 1997; Hardiker, 1981; Nikitina et al., 2015; Slastenin, 2004; Zakharchuk, 2006). In some works the essence of education`s personalization is discussed (Asmolov, 2008; Bim-Bad, 1994; Onushkin \& Ogarev, 1999; Schelten, 2005). However, the problem of scientific substantiation of implementing a personalized approach in the system of "helping" professions specialists` postgraduate education can be classified as the least developed part of modern pedagogical science.

\section{Literature Review}

A comparative analysis of scientific and pedagogical literature on the problem of education `s personalization allowed to state that this concept is interpreted as:

- A factor of student's cognitive activity development (Osmolovsky, 2006);

- A special form of educational process organization, taking into account the peculiarities of students 'individual differences (Nikitin, 2003);

- One of the directions of the continuous professional education system modernization (Melechina, 2008);

- A process, aimed at developing students` abilities and interests (Unt, 1990);

- Means of individual educational program building (Ogarev, 2005).

- Didactic principle according to it, the content and all other elements of educational process should be determined and based on the interests, needs and aspirations of people involved in training activities (Onushkin \& Ogarev, 1999).

- Personalized approach in the system of social sphere specialists` postgraduate education is implemented in the context of pedagogy support paradigm (Gazman, 1999), humanistic, person-centered education paradigms (Amonashvili, 1990; Volenko \& Nikitina, 2010; Wulfov, 2002).

\section{Methods and Data}

In the article there are results of experimental verification (in the period from 2002 to 2015) of personalized approach implementation model in the system of postgraduate education of "helping" professions specialists on the basis of faculties of professional skills improvement and professional retraining of Russian State Social University (RSSU) in Moscow, Kursk (Russia), Kuban State University (Krasnodar, Russia), Moscow Humanitarian Pedagogical Institute (Moscow).

All participants of professional retraining programs (over 500 hours) in the areas of "Social Services Manager", "Management of Disabled People Rehabilitation", "Education Manager", "Social Pedagogy", " Rehabilitation Services Management" took part in the experimental work, as well as students of a number of retraining courses from 72 to 244 hours. At various stages of the experiment the study covered 3247 students of "helping" professions specialists postgraduate education system (social workers, psychologists and social teachers of social protection, health, education institutions), 253 training courses teachers, 368 practitioners, who supervised students` internship.

During experimental verification of the model these tasks were solved: definition of initial level of different kinds of competences formation of the training students; motivation students to develop their professional competencies system; interaction of different departments faculty members on providing the personalized education content; implementation of gradual development of new competencies technology, development of professionally important qualities of a social 
sphere specialist; analysis of results and monitoring of the professional competence formation level of postgraduate education graduates of "helping" professions specialists.

At the initial stage of the experimental work a diagnostic of level of students ' professional competences formation, level of knowledge, skills and abilities required to perform various types of a specialist's functional was carried out. The tools used for diagnostic included: interviewing, interrogation, self-assessment, observation, methods of mathematical statistics. The obtained data showed that every third respondent had difficulties in new technologies implementation in social work, education management, and social sphere management. $55 \%$ of respondents indicated their subjective necessity of mastering some methods of social sphere expert`s personality professional deformation prevention.

\section{Results}

\subsection{Design of Personalized Approach Model Implementation in the System of "Helping" Professions Specialists Retraining}

The authors identified following functions of personalized approach in the system of "helping" professions specialists postgraduate education:

- Diagnostic and prognostic function (involves diagnosis, identification, disclosure, and then development of professional and personal potential of a specialist-training course student);

- Adaptive-environmental function (provides operational professional retraining in dynamic changes in sociopersonal and professional situations of a specialist's life; promoting the integration in an unfamiliar professional, socio cultural context);

- Structurally transformative function (improving professional qualification of a specialist; general and professional culture development; assistance in career planning implementation; improving professional social mobility, competitiveness);

- Professional-specializing function (formation special "helping" profile specialist competences taking into account their socio-professional specialization, qualification and professional requirements);

- Reflexive compensatory function (updating the reflexive position of an employee; formation of life compensatory mechanisms; increasing opportunities for social, personal and professional success, subjects' personal fulfillment and self-development);

- Creative-developmental function (progressive enrichment of specialists`creative professional and personal potential; professional thinking divergent development);

- Preventive function (prevention of an expert's personality emotional burnout and professional deformation processes).

- The model of personalized approach implementation in the system of "helping" professions specialists" postgraduate education involves the following modules interrelation:

- Functional-target module (reflects personalized guidelines of students' professional and personal growth, especially individual vocational educational routes implementation, individually-driven trajectories of specialists` professional competence and culture development);

- Substantial-problem module (includes professionally-applied and practice-oriented training courses disciplines content that provides professional and personal growth of a specialist, his educational needs satisfaction);

- Organizational and technological module (includes a set of different educational technologies, as well as methodological, material and technical support of training process);

- Praxeological module (active accumulation of personal experience of professional mastered competencies existence in the frames of different practices and internships; forms of students' research activity development;

- Effective integrative module (includes monitoring the quality of coursework and vocational education programmes with the involvement of external expert systems; each students' individual professional social portfolio existence taking to account his subject, real or potential places of employment).

4.2 Stages and Principles of Implementation of the Model Personalized Approach in the Training of Specialists "Helping" Professions

Stages of implementation of the model are:

- Analytical-marketing stage (includes analysis of the demand for specialists in a particular region to "help" the 
profile of various levels of qualification and specialization, demand forecasting trends variativnyh vocational education services, and to improve the skills of these professional refresher training);

- Diagnostic and orientation phase (includes definition of the specificity of the contingent of adults enrolled in training courses, identifying their actual and potential professional and educational needs and opportunities in the field of professional and personal growth);

- Organizational and procedural phase (includes design and implementation of scientific and methodological support of all forms, directions, personalized kinds of additional vocational education, a system of measures to enhance the innovation of all structural units of the University in the personification of continuous professional training social profile specialists);

- Expert-monitoring stage (multi-factor provides expert evaluation of the effectiveness of the implementation of variant individualized programs of postgraduate education).

- The main principles of the implementation of the model are:

- The principle of potentiality (based on the assumption that every adult learner has a tendency to selfdevelopment, to the intention of professional and personal integrity, disclosure and development capabilities, vitagennogo resources);

- The principle of relevance (includes matching content-methodological basis of course training programs to the needs of adult learners, as well as the changes taking place in society, science, technology, implementation of postgraduate professional education process);

- The principle of mainstreaming and socio-pedagogical support of individuality adult learner (involves the creation of conditions conducive to the acquisition of practitioners experience self-awareness as a subject in various activities, the provision of adult learners need help and support to overcome difficulties; the emotional comfort of the listener in the pedagogical interaction with teachers courses, establishment of educational activity situations in which adult learners can express their individuality);

- The principle of activation and development of vocational education of subject positions adult learning (each student is involved in the design of their own professional and educational route in accordance with the personal cognitive abilities and professional-oriented claims to himself as a specialist, he has the opportunity to correction in view of the results achieved and experience educational and professional activities);

- The principle dialogization (assumes priority of interactive learning technologies; development of the activity, initiative, responsibility, reflexivity all stakeholders continuous training);

- The principle of clustering (provides for the implementation of personalized vocational training programs in various fields for practitioners of different levels of skill and specialization. Cluster vocational educational programs of postgraduate education is characterized by: common ultimate goals, the joint management structure, they are built on professional and personal interaction of all educational subjects process, to establish programs and evaluating their effectiveness brought various experts, which allows to reconcile the interests of all participants of the educational program).

\subsection{Substantial and Technological Bbasis of the Implementation of the Model}

In the course of many years of experimentation authors on faculty training and retraining of a number of Russian universities have been identified the following types of the most popular clustered personalized professional educational services in the graduate education of specialists "helped" profile:

- Functional-technological training courses (to help carry out specific types of high quality functional specialist with the qualification requirements, such as training courses "Technology advocacy of social pedagogue" (108 hours), "Technology okkupatsional therapy in the work of the expert in social work" (144 h), "System of social and rehabilitation techniques in working with children with disabilities" (136 h), "Modern methods and technologies of social and educational prevention of deviant behavior of minors" (144 h));

- Compensatory courses (fill shortcomings comprehensive, cultural training needed for productive passage of a certain period of life expert, to improve the overall personal and professional culture of a specialist, for example, training courses "Information culture specialist social sphere" (144 hours), "Ethnopedagogical Culture specialist Youth Work" (136 h));

- Adaptive-remedial courses (necessary to change some personal, behavioral, communication and other manifestations of a specialist to improve the professional, social and cultural adaptation of personality, such as the continued relevance of the courses "Conflict competence expert in social work" (156 hours), "Professionalcommunicative Culture expert of social sphere "(188 h),"Confessional tolerance specialist sotsionomicheskogo 
Profile"(158 h));

- Professional-valeological courses (designed for successful completion of the various phases and the solution of certain problems difficult periods professiogenesis help to overcome the crisis, for example, courses on "Occupational health specialist sotsionomicheskogo Profile" (204 hours), "Prevention of professional deformation of the expert in social work" (186 h), "Modern methods and technologies of preventing burnout social teacher" (188 h));

- Specialized-application training courses (due to constant updating of information and professional context, the development of theoretical and methodological foundations sotsionomicheskoy work in modern society and the laws of development of professional and life issues specialist, meeting the needs of the specialist in the new practice-oriented vocational and applied knowledge, serve as an addition to the substantial existing knowledge, skills, for example, courses on "Modern methods and technologies of social career guidance teacher residential institutions for minors" (144 hours), "Psychological and pedagogical basis for preventing neglect of minors under social assistance centers for children and families" (156 h), "New technologies and social rehabilitation of persons with disabilities" (144 h), "Specialized Gerontological-applied methods and technologies of interaction expert in social work with the elderly" (186 h));

- Professional-prolonged course (done propaedeutic function to resolve situations that arise in professional development specialist, can be designated as "knowledge for the future, "for example, so-called "reserve managers" demand for retraining programs "Organization Management Rehabilitation" (508 hours) "Management in the social sphere" (502 h), course "Management culture specialist social sphere" (144 h); for professionals engaged in international partnerships demand courses "Professional-communicative competence of foreign language specialist social sphere" (204 h));

- Administration and management courses (designed to improve various aspects of the professional activity of managers, administrative and managerial staff of social institutions, such as the program "Fundraising in the management of social institutions" (108 hours), "Qualimetric competence of the head offices of the social sphere" (108 h), "Strategic Management in the management of social institutions" (144 h));

- Creative-educational courses (a stimulus to professional and individual development specialist disclosure capabilities, stimulate the manifestation of professional creative activity of specialist social services, for example, the program "Methods of art therapy in the professional activity of the social teacher" (204 hours), "Methods and techniques of social and cultural rehabilitation of persons with disabilities "(144 h));

- Research courses (demand specialist social services, performing research, is a graduate student, doctoral students, for example, courses on "Methods of content analysis in the social and educational work" (144 hours), "Innovative models of integration of persons with disabilities in the modern society" (156 h), "Methodological approaches to the design of social processes and systems "(136 h), "Paradigms of implementing the mission of social work in modern society "(108 h)).

\subsection{Data Analysis of Diagnostic Techniques}

An indication of the effectiveness of implementation of the model personalized approach in the training of experts to "help" occupations is fairly high satisfaction index trainees various parties organizing the educational process (Table 1).

Table 1. Satisfaction Index graduates training and retraining RSSU implementing personalized approach (edition 2011 year / edition 2014 year; the number of respondents in each sample of about 200 people)

\begin{tabular}{|c|c|c|c|}
\hline \multirow[b]{2}{*}{ Index satisfaction } & \multicolumn{3}{|c|}{ Retraining programs } \\
\hline & $\begin{array}{l}\text { The manager of the } \\
\text { social sphere }(502 \mathrm{~h})\end{array}$ & $\begin{array}{l}\text { Social pedagogy } \\
(502 \mathrm{~h})\end{array}$ & $\begin{array}{l}\text { Manager education } \\
(502 \mathrm{~h})\end{array}$ \\
\hline $\begin{array}{l}\text { Satisfaction Index personification of educational content (keeping the content } \\
\text { of the courses of individual professional and educational needs of students, } \\
\text { the formation of knowledge, skills needed in a competitive labor market; } \\
\text { practice-oriented teaching staff copyrighted materials, materials of leading } \\
\text { domestic and foreign scholars and practitioners sotsionomicheskoy sphere; } \\
\text { variability and efficiency of administration at the request of students elective } \\
\text { courses, workshops) }\end{array}$ & $0.52 / 0.82$ & $0.56 / 0.75$ & $0.63 / 0.78$ \\
\hline $\begin{array}{l}\text { Satisfaction Index personification of organization of educational process } \\
\text { (implementation of an individual approach to the educational activities of the } \\
\text { listener, the application of interactive, information-computing, modular, }\end{array}$ & $0.63 / 0.83$ & $0.61 / 0.78$ & $0.62 / 0.75$ \\
\hline
\end{tabular}


distance learning technologies; variability of forms and methods of self-

educational activity of students, and others.)

The index of satisfaction with the organization professional practice

(individual approach in choosing the internship databases; personification

selection manager, methodologist internship, individual approach to

$0.57 / 0.85$

$0.56 / 0.73$

$0.52 / 0.77$

counseling and support activities listener during the internship, etc.).

Satisfaction Index personification of research activities (the individualization

of interaction with teachers when the Student research; variability of forms of

participation in scientific research: scientific conferences, publishing articles,

research findings, meetings with scientists, the variability of forms and

methods of scientific research students, and others.)

In Table 1, the index of satisfaction with the course participants is calculated on the basis of application of mathematical methods of multidimensional scaling, in particular, using a scale Gutmann, for array processing sociological data as an average on a five ordinal scale. The index value changes in the range from (-1) to (+1). The value $(-1)-$ the absence of $100 \%$ of respondents satisfied with the results; (1) -its presence in $100 \%$ of the respondents; (0) $-50 \%$ of respondents are fixed in terms of the satisfaction, and the other half-its absence. Of particular interest in the delayed control of an independent professional activity "helps" profile (students training system) presented diagnostics level of professional deformation of practitioners (participants in the experiment). It was used method of determining profdeformatsiya social worker S. Jackson adaptation N. E. Vodopyanova (Table 2).

Table 2. Mean values of subscales of the questionnaire "Syndrome profdeformatsiya social worker" (edition 2011 year I edition 2014 year; the number of respondents in each sample of about 200 people; subjects were consistently within two to three years, mastered several programs in the courses RSSU training from 72 hours to 508 hours)

\begin{tabular}{lccccc}
\hline \multirow{2}{*}{ Groups } & Average age & $\begin{array}{c}\text { Experience } \\
\text { employment }\end{array}$ & $\begin{array}{c}\text { Emotional exhaustion } \\
(\max 54)\end{array}$ & $\begin{array}{c}\text { Sepersonalization } \\
(\max 30)\end{array}$ & $\begin{array}{c}\text { The reduction of personal } \\
\text { achievements (max 48) }\end{array}$ \\
\hline $\begin{array}{l}\text { Specialists Social Work } \\
\text { (study participants) }\end{array}$ & 26 & $3-5$ years & $26.5 / 21.3$ & $11.8 / 8.4$ & $26.3 / 18.5$ \\
$\begin{array}{l}\text { Specialists Social Work } \\
\text { (databases internship) }\end{array}$ & 26 & $3-5$ years & $28.4 / 27.6$ & $15.7 / 13.8$ & $34.2 / 28.3$ \\
$\begin{array}{l}\text { Specialists Social Work } \\
\text { (study participants) }\end{array}$ & 37 & $6-10$ years & $33.2 / 28.7$ & $16.3 / 13.6$ & $32.4 / 23.7$ \\
$\begin{array}{l}\text { Specialists Social Work } \\
\text { (databases internship) }\end{array}$ & 37 & $6-10$ years & $37.8 / 35.2$ & $21.8 / 18.5$ & $38.5 / 35.4$ \\
$\begin{array}{l}\text { Specialists Social Work } \\
\text { (study participants) }\end{array}$ & 48 & $11-16$ years & $41.5 / 36.5$ & $18.9 / 16.2$ & $33.7 / 30.2$ \\
$\begin{array}{l}\text { Specialists Social Work } \\
\text { (databases internship) }\end{array}$ & 48 & $11-16$ years & $48.6 / 43.1$ & $23.5 / 21.2$ & $41.6 / 42.8$ \\
\hline
\end{tabular}

In 2014, a survey was conducted of students training courses and professional training of the Russian State Social University (386 respondents - social professionals aged 23 to 60 years). As a result of responses to the question: "Which technologies, forms of organization of educational process in the system of postgraduate education attracts you the most?" The overwhelming majority of respondents were in favor of interactive learning technologies (which provide an interactive subject-subject basis of educational and professional interaction between adult learners and teachers). They were singled out training and workshops, as well as visiting classes in different types of social institutions. The survey voted in favor of training of $21 \%$ of respondents, master classes-20.5\% expressed a preference for visiting lessons$25.5 \%$ of respondents; Business games-11\%. Lectures, seminars and practical noted respectively-6.5\%; $8.5 \%$; $7 \%$ of students. This result indicates the desire of students to dive into the issues under investigation, to decide the professional tasks to simulate a situation of social and professional practice, design and design different approaches to professional activities.

As a result of implementation of the model personalized approach in the training of specialists "helping" professions were analyzed with the assistance of experts as employers, organizations and institutions whose work experts who have undergone professional training program "Management of organization Rehabilitation", "Management of the provision of rehabilitation services". The analysis allowed us to determine the qualitative results of these programs, as follows: Maturity of trainees skills in the productive use of technologies of social partnership in the provision of 
rehabilitation services, ability to effectively implement the technology and methods of family therapy, family and household Rehabilitation, formation of professional and practical skills of the marketing Research in the provision of rehabilitation services, fundraising skills to use in the practice of rehabilitation of the disabled; development of social and professional mobility, research competence management organization Rehabilitation.

\section{Discussion}

Experimental work conducted by the authors in a period of fifteen years, showed that the effectiveness of personalized approach implementation and the effectiveness of professionally important qualities formation and "helping" professions specialists professional competencies in terms of retraining faculties were provided by:

- Specific contingent of adult students and further base on the logic of their professional and personal development;

- Development and implementation of personalized cluster training programs based on scientific analysis and understanding the results of marketing current and future needs of the labour market in the social sphere specialists of different skill levels and specialization;

- Changing the content of training and retraining courses by integrating fundamental knowledge of an interdisciplinary nature, on the one hand, and their professionally applied orientation, on the other;

- Replacement of information and algorithmic type of training courses to problem-solving, design, interactive, context-environmental training;

- Targeted development of students` reflective culture as an integral component of social sphere specialists learning and professional activity;

- Replacement of question-answering postgraduate professional training techniques aimed at mastering reproductive and formal-logical thinking to methodology developing content-heuristic, creative side of specialist's professional thinking;

- Implementation of system for monitoring the quality of social sphere specialists` personalized post-graduate education, providing subsequent appropriate actions aimed at improving the substantial-technological basis of the training.

- Identified above didactic factors for successful personalized approach implementation in the system of "helping" professions specialists` postgraduate education can be considered as recommendations for organizational-technological and informative-methodical bases improvement in institutions engaged in advanced training and professional retraining of social sphere specialists.

- Criteria of personalized approach of implementation results in the system of social profile specialists retraining are:

- Subjective-personal criterion (increased competitiveness level of a specialist on the modern labour market, professionalism development through upgrading professional competencies and professionally important qualities; satisfaction level increase of specialist's professional activities and career development prospects results; development of specialist `s professional mobility; self-educational culture development as a critical component of practitioner `s professional and personal culture; creative activity identification and development; decrease level of personality emotional burnout and professional deformation);

- Professional objective criterion (increase level of employers, clients of social services satisfaction by the results of professional activity of specialists, providing promotion track);

- Constructive didactic criterion (development of forms, technologies of personalized continuing professional education, modernization of additional professional education for various fields specialists programmes content, improving the quality of educational material perception through its adaptation to the physiological level of an adult student; professional and creative activity of faculty members in andragogical area level increase that contributes to the development and implementation of new content and technological support of variable, diversified professional-educational services).

\section{Conclusion and Final Considerations}

Personalized approach in the system of social sphere specialists' postgraduate education is a response to the objective needs of the time associated with vocational educational services market development and dynamic changes in social infrastructure of Russian society, increasing competition on the labour market. This approach is demanded by "helping" profile specialist in order for his personal and professional development, change of occupation. 
Personalized approach contributes to the social sphere staff training, able to adapt to professional environment changes, promotes personal and professional self-determination, professional and personal growth of a specialist. The approach is based on the understanding and approval of the individuality of each adult student's uniqueness, the importance of his subjective nature, the value of his life experience, that is, the priority of individual personality in a man.

In theoretical interpretation personalized approach is understood as creating prerequisites and conditions for transition of changing subject of education to a new, higher level of professional and personal development; as a substantial characteristic of studying content adaptability to the characteristics of students taking into account their socioprofessional activity.

Presented in this article material does not exhaust all aspects of complex, multi-faceted problem of personalized approach implementation in terms of "helping" professions specialists ' postgraduate education system. Further research directions may include: a) improving monitoring and evaluation, qualitative procedures for determining the quality of personalized professional educational programs implementation in system of professional skills improvement and professional retraining of social profile specialists; b) theoretical and methodical bases development of specialized teachers 'training to implement their personalized approach in the process of adult practitioners education; $c$ ) study of specific personalized approach implementation in terms of remote forms of social sphere specialists' training and professional retraining.

\section{Acknowledgements}

This article was prepared in the framework of the state task of Ministry of Education and Science of Russian Federation 2014/601 (project code 3106).

\section{References}

Amonashvili, S. A. (1990). Personal-humane basis of the pedagogical process. Minsk, Belarus Republic: Publishing center "University education".

Angell, R. J., Heffernan, T. W., \& Megicks, P. (2008). Service Quality in Postgraduate Education. Quality Assurance in Education, 16(3), 236-254.

Arnold, R. (1983). Pädagogische Professionalisierung betrieblicher Bildungsarbeit. Frankfurt a.Main, Germany: Verlag Peter Lang.

Asmolov, A. G. (2008). Strategy of socio-cultural modernization of education: On the way to overcoming the crisis of identity and the construction of civil society. Issues of education, 1, 65-76.

Asmolov, A. G., Verbitsky, A. A., \& Gusairov, M. B. (1993). On the methodological bases of functioning and development of system of continuous education in the context of multi-level training. Higher school of Russia, 1, 22-28.

Barsky, A. (2009). Ethics and values in social work: An integrated approach for a comprehensive curriculum. New York, NY: Oxford University Press.

Bim-Bad, B. M. (1994). The anthropological basis of the theory and practice of contemporary education. Moscow, Russian Federation: The University of the Russian Academy of education.

Bitusikova, A., Bohrer, J., Borošic, I., Costes, N., Edinsel, K., Holländer, K., Jacobsson, G., Jakopovic, I., \& Mulder, F. (2010). Quality Assurance in Postgraduate Education (ENQA Workshop Report 12). Workshop Report.

Bocharova, V. G. (1999). Professional social work: The personality-oriented approach. Moscow, Russian Federation: Institute of pedagogy of social work of Russian Academy of education.

Brennan, J. (2001). Training for life, for employment and equality. Sociology of education, 7, 5-13.

Correa, A. (1973). Permanent Education and Adult Education in Brasil. Rio de Janeiro, Brasil.

Doel, M., \& Shardlow, S. (Eds.). (1997). Teaching social work practice: An international perspective and prospects. Moscow, Russian Federation: Publishing center "Aspect-press".

Gazman, O. S. (1999). Education and pedagogical support in education. Moscow, Russian Federation: Publishing house of the Pedagogical society in Russia.

Hardiker, P. (1981). Heart and head the function and role of knowledge in social work. Issues in Social Work Education, 1, 85-111.

Melechina, E. A. (2008). The role of lifelong learning in the professional development of the teacher. Pedagogical education and science, 12, 25-33.

Nikitin, E. M. (2003). Andragogy: history and modernity. The Federal system of improvement of professional skill of educators. Moscow, Russian Federation: Academy of advanced training and professional retraining of education workers.

Nikitina, N. I., Romanova, E. Y., Komarova, E. V., Tolstikova, S. N. \& Grebennikova, V. M. (2015). Qualimetric methods in the evaluation of the quality of professional training of specialists in social work. Review of European Studies, 3(7), 66-79.

Ogarev, E. I. (2005). Continuing education: Basic concepts and terms. St. Petersburg, Russian Federation: Institute of adult education of Russian Academy of education.

Onushkin, V. G. (1989). Continuing education is a priority direction of science. Soviet pedagogy, 2, 16-23. 
Onushkin, V. G. \& Ogarev, E. I. (1999). The personification of education. In S. J. Batyshev (Ed.), Encyclopedia of education (Vol. 2, pp. 246-247). Moscow, Russian Federation: Academy of professional education.

Osmolovsky, I. M. (2006). Didactics. Moscow, Russian Federation: Publishing house "Academy".

Schelten, A. (2005). Begriffe und Konzepte der berufspädagogischen Fachsprache. Stuttgart, Germany: Franz Steiner Verlag.

Slastenin, V. A. (Ed.). (2004). Pedagogy of vocational education. Moscow, Russian Federation: Publishing house "Academy".

Sumi, T. S. (2007). Diversification of continuous professional education of specialists in social work at the University (PhD thesis). Moscow, Russian Federation: Russian State Social University.

Unt, I. (1990). Individualization and differentiation of instruction. Moscow, Russian Federation: Publishing house "Pedagogy".

Wershlowski, S. G. (2002). Adult as a subject of education. Pedagogy, 8, 6-11.

Volenko, O. I. \& Nikitina, N. I. (2010). To the question about the pedagogical paradigms of modern professional education of specialists of social sphere. Innovations in education, 6, 4-16.

Wulfov, B. Z. (2002). Pedagogy of reflection. Moscow, Russian Federation: Humanitarian Pedagogical Institute.

Zakharchuk, L. M. (2006). Professional and personal development specialist in social work in terms of University system (PhD thesis). Moscow, Russian Federation: Russian State Social University.

Zmeev, S. I. (1999). The basics of andragogy. Moscow, Russian Federation: Publishing house "Flinta". 